\title{
Intensification of mass transfer in liquid fluidized beds with inert particles $^{1}$
}

\author{
J. Yang, A. Renken* \\ Institute of Chemical Engineering, Swiss Federal Institute of Technology, CH-1015 Lausanne, Switzerland
}

Received 23 December 1997; received in revised form 15 April 1998; accepted 1 June 1998

\begin{abstract}
The influence of inert particles on liquid/solid mass transfer is studied in fluidized beds by using a binary-mixture of solids of differing size and density. The addition of inert particles of higher density and smaller diameter, e.g. glass beads, exerts remarkable effects on mass transfer coefficients in comparison to that of mono-component active particles at the same liquid velocity. The extent of the effect on liquid-solid mass transfer coefficients increases with an increasing fraction of the small inert particles in the mixture. The liquid-solid mass transfer coefficients for binary-mixtures are well correlated in terms of dimensionless groups and the voidage parameter. (C) 1998 Elsevier Science S.A. All rights reserved.
\end{abstract}

Keywords: Mass transfer; Inert particles; Mixing; Stratification; Fluidized bed.

\section{Introduction}

In general, solid particles of different size and/or density are segregated axially in liquid fluidized beds depending on the difference in their properties, smaller particles above the larger, or lighter particles above the heavier. When the smaller particles have the higher density, the opposing effects of those physical properties on the fluidizability of two kinds of solid particles can result in quite unpredictable behavior: segregation, mixing or partial mixing. Considerable work was carried out to explain the complex hydrodynamic behavior of the binary solid fluidization and the 'solids layer inversion' phenomenon has aroused widespread interest [1-14]. However, the practical application of the presence of different particles in fluidized beds and the influence of mixing phenomena of binary solid systems on liquid/solid mass transfer has seldom been studied. In the present paper, the effect of inert heavier/smaller glass beads (GB) on liquid mass transfer to larger particles with lower density is reported.

\footnotetext{
* Corresponding author. Tel.: +41 21 6933181; fax: + 4121 6933190; e-mail: albert.renken@epfl.ch

${ }^{1}$ This contribution is dedicated to the remembrance of Professor Jaques Villermaux.
}

\section{Experimental}

\subsection{Active and inert particles}

The active particles are cation-exchange resins (Diaion SK116). They are obtained from Supelco SA., Switzerland, which sold material originally produced by Mitsubishi Chemical Industries. All of the active particles are spherical except for a few broken resins. The inert particles are glass beads which are closely screened to obtain a narrow size distribution.

The volumetric mean particle diameters were measured by the particle sizer (Particle Sizer 2600E Malvern, Spring Lane GB). The apparent density of particles $\rho_{\text {ap }}$, was determined by the correlation of Schiller-Naumann [15] by measuring the terminal velocities of selected particles:

$\mathrm{Ar}=18 \mathrm{Re}_{\mathrm{t}}+2.7 \mathrm{Re}_{\mathrm{t}}^{1.687}$

$3.6<\mathrm{Ar}<10^{5} \quad 10^{-3}<\mathrm{Re}_{\mathrm{t}}<10^{3}$

where $\mathrm{Ar}$ is Archimedes number, and $\mathrm{Re}_{\mathrm{t}}$, the terminal Reynolds number. The results were confirmed picnometrically.

The size distribution of the particles can be described by a normal distribution function. The standard deviation (SD) and relevant properties of active resins and glass beads are listed in Table 1. 
Before use, the ion exchange resins are pretreated under the following conditions: The resin is first placed in an alkaline solution $(2.5 \mathrm{~N})$. The suspension is stirred and heated at $60^{\circ} \mathrm{C}$ for $\sim 1 \mathrm{~h}$ and then cooled down naturally. The resin is recovered by filtration and washed until the washing water has a $\mathrm{pH}$ lower than 9 . Subsequently, the resin is placed in a beaker of sulfuric acid solution $(5.5 \mathrm{~N})$. The suspension is stirred and heated at $60^{\circ} \mathrm{C}$ for $\sim 1 \mathrm{~h}$ and then cooled down naturally. The resin is filtered and extensively washed again until the $\mathrm{pH}$ of the washing water is above 5. The resin is then stored in distilled water. The same procedure is also used for the regeneration of spent particles.

\subsection{Experimental set-up and procedure}

Fig. 1 illustrates a schematic diagram of the experimental set-up which consists of a glass column of 39 $\mathrm{mm}$ inner diameter and $600 \mathrm{~mm}$ length. The liquid flow enters at the bottom of the bed and passes through a distributor to avoid radial velocity gradients. The column is provided with a thermostat double-jacket to control the temperature. All of the experiments were performed at $20 \pm 0.3^{\circ} \mathrm{C}$.

For the measurement of mass transfer coefficient, known quantities of active and inert particles are introduced at the top of the column at the beginning of each run. An alkaline solution is fed from the tank to a buffer which is designed to maintain the stability of flow rate and pumped by a gear pump into the fluidized bed reactor. The mass flow rate is recorded at the outlet of the reactor with a balance. Neutralization of a sodium hydroxide solution by the strong acid ion exchange resin occurs in the fluidized bed reactor and the conversion of sodium hydroxide in the liquid is determined by measuring the ion concentrations of the solutions in the feed and at the exit of the reactor with an on-line conductivity-meter under stationary conditions.

The ion exchange resins are regenerated after three to four runs.

\subsection{Determination of mass transfer coefficient}

The mass transfer coefficient can be obtained from the steady-state mass balance equation. Normally, in a shallow fluidized bed, plug flow with no axial dispersion can be assumed [16]. Another way to neglect axial liquid dispersion is to dilute the active compound with inert materials in order to obtain a deep fluidized bed [17]. The material balance for $\mathrm{Na}^{+}$ions in the liquid phase for a differential volume element of the column is given by:

$u \frac{\mathrm{d} C}{\mathrm{~d} z}=-\frac{6(1-\varepsilon)}{\bar{d}_{\mathrm{p}}} k_{\mathrm{L}}\left(C-C^{*}\right)$ where $C^{*}$ is the equilibrium $\mathrm{Na}^{+}$ion concentration at the liquid-solid interface. Since the exchange of $\mathrm{Na}^{+}$ and $\mathrm{H}^{+}$occurs instantaneously and the loading of $\mathrm{Na}^{+}$ions in the resin is kept at a very low level, it is assumed that $C^{*}$ is negligible compared to the bulk concentration $C$. The integration and rearrangement of Eq. (2) leads to

$k_{\mathrm{L}}=\frac{Q}{A} \cdot \ln \frac{C_{\text {in }}}{C_{\text {out }}}$

where $C_{\text {in }}$ and $C_{\text {out }}$ are the concentration of $\mathrm{Na}^{+}$ions in the feed and effluent solution respectively, $Q$ is the volume flow rate of the feed and $A$ is the total surface area of the particles in the bed. The surface area of active particles is estimated from Eqs. (4) and (5):

$\varepsilon_{0}=\frac{V \cdot \rho_{\text {ap }}-m}{V \cdot\left(\rho_{\text {ap }}-\rho\right)}$

$A=V \cdot\left(1-\varepsilon_{0}\right) \cdot 6 / \bar{d}_{\mathrm{p}}$

where $V$ is the volume of resin and water in a pycnometer, $\bar{d}_{\mathrm{p}}$ represents the mean diameter of the particles; $m$, the mass of resin and water, $\rho$, the density of water, and $\rho_{\text {ap }}$, the apparent density of active resins.

The effective diffusion coefficient is calculated by the geometric mean of the individual diffusivities of the two species [18]:

$D_{\text {eff }}=\frac{2 D_{\mathrm{Na}^{+}} D_{\mathrm{OH}^{-}}}{D_{\mathrm{Na}^{+}}+D_{\mathrm{OH}^{-}}}$

The effective diffusion coefficient is constant at a given temperature.

\section{Results}

\subsection{Mixing of binary solid particles}

When the binary mixture is fluidized by a liquid, the stratification pattern changes with liquid velocity as shown in Fig. 2. At low superficial velocities, particles are stratified in two layers, the layer of glass beads (small particles) is below the layer of active resins (a). With increasing liquid velocity the population of the lighter/larger resin particles in the lower layer of glass beads increases (b). Further increase in the liquid veloc-

Table 1

Particle properties

\begin{tabular}{lllll}
\hline Substance & $\bar{d}_{\mathrm{p}}(\mu \mathrm{m})$ & $\mathrm{SD}(\mu \mathrm{m})$ & $\rho_{\text {ap }}\left(\mathrm{kg} \mathrm{m}^{-3}\right)$ & $\mathrm{Ar}(-)$ \\
\hline $\begin{array}{l}\text { Active resins (AR) } \\
\text { Diaion SK116 (in } \\
\quad 614\end{array}$ & 135 & 1320 & 715 \\
$\begin{array}{l}\mathrm{H}^{+} \text {form) } \\
\begin{array}{l}\text { nert particles } \\
\text { Glass beads (GB) }\end{array}\end{array}$ & 176 & 38 & 2450 & 76 \\
\hline
\end{tabular}




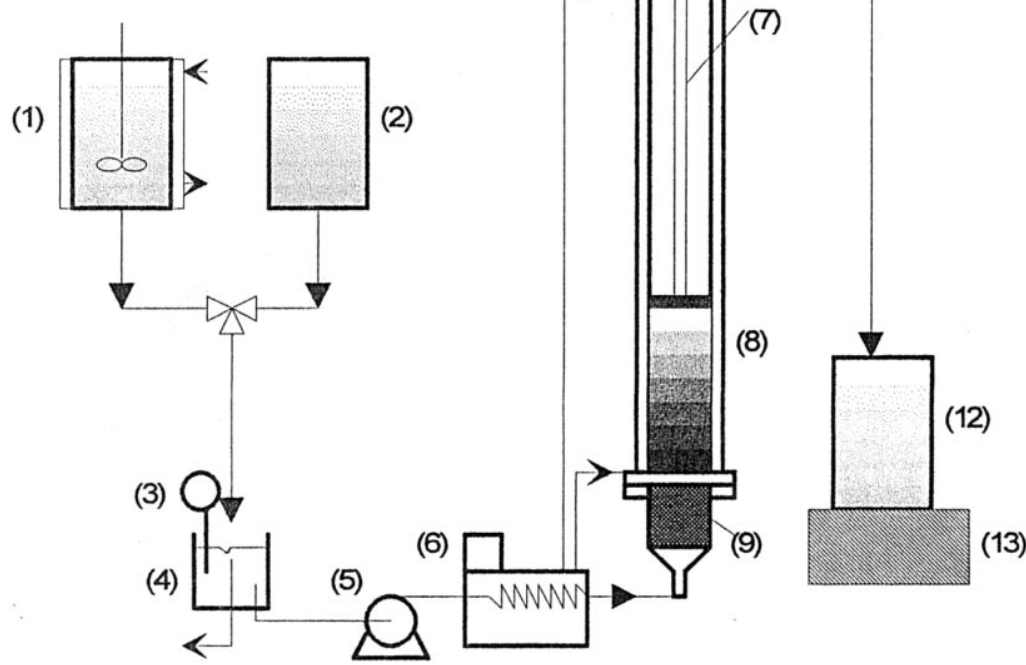

Fig. 1. Schematic diagram of experimental apparatus. 1, Tank (Solution of NaOH); 2, Tank (Water); 4, Buffer; 5, Gear pump; 6, thermostat; 7, Movable piston; 8 Fluidized bed ( $\phi=39 \mathrm{~mm}, L=600 \mathrm{~mm})$; 9, Calming section, 3; 10, Conductivity-meter; 11, On-line cell; 12, Reservoir; 13, Balance.

ity results in higher expansion of the fluidized bed and a better mixing of the two different particles. At a liquid velocity $\left(u=u_{\mathrm{m}}\right)$, nearly complete mixing of components occurs (c): the active resin particles are uniformly dispersed from down to bottom of the bed at a maximum height of binary mixture. A further increase in the liquid velocity $\left(u>u_{\mathrm{m}}\right)$ leads to a migration of the smaller glass beads to the upper layer and a decrease of the amount of glass beads remaining in the active resin layer. In parallel, the height of mixing zone is reduced (d).

In contrast to several authors [5,19], no complete layer inversion phenomenon is observed. This discrepancy of mixing states can be attributed to the different particle properties, e.g. size distribution, difference of densities, and also the overall bed composition. The mixing state (c) in this work has also been observed by Jean and Fan [12] and Gibilaro et al. [11]. The observed mixing behavior can be considered as 'gradual layer transposition'.

For the above case, the top surface heights of the active resins layer $h_{\mathrm{AR}}$ and of the glass beads layer $h_{\mathrm{GB}}$ are shown in Fig. 3 as a function of the superficial liquid velocity. For comparison, the expansion characteristic of the mono-component system of active resins is shown in the same figure.

When the composition of the binary particles fluidized bed is varied, the maximum mixing height and the optimal mixing velocity of the liquid $u_{\mathrm{m}}$ is changed. For a given amount of active resins, the mixing velocity $\left(u_{\mathrm{m}}\right)$ decreases with an increasing volume fraction of glass beads:
$f_{\mathrm{GB}}=\frac{V_{\mathrm{GB}}}{V_{\mathrm{GB}}+V_{\mathrm{AR}}}$

where $V_{\mathrm{GB}}$ and $V_{\mathrm{AR}}$ are the volumes of glass beads and active resins in the mixing layer, respectively.

The fraction $f_{\mathrm{GB}}$ represents the mixing capacity of the glass beads in the active resin at the optimal mixing liquid velocity $u_{\mathrm{m}}$. The change of the optimal mixing liquid velocity $u_{\mathrm{m}}$ as a function of the volume fraction of glass beads $f_{\mathrm{GB}}$ is shown in Fig. 4 for various compositions in the mixing layer. With a decrease in the volume fraction of glass beads in the mixture from 85 to $20 \%$, the mixing liquid velocities $u_{\mathrm{m}}$ increase from 9 to $\sim 11.7 \mathrm{~mm} \mathrm{~s}^{-1}$.

The relationship between optimal mixing velocity and composition in the mixing layer is given by the following equation:

$u_{\mathrm{m}}=11.9-3.3 \cdot 10^{-4} f_{\mathrm{GB}}^{2}$

\subsection{Effect of inert particles on mass transfer coefficients}

A binary mixture of particles consisting of $10 \mathrm{ml}$ of active resins and $30 \mathrm{ml}$ of glass beads as inert particles was employed. The mass transfer coefficients were measured at different liquid velocities corresponding to different mixing states. The experimental results from binary- and mono-component systems are shown in Fig. 5 . When the liquid velocity is low, only a small part of active resin is mixed with glass beads (Fig. 2 (a)). The effect of the inert particles on mass transfer is negligible. 


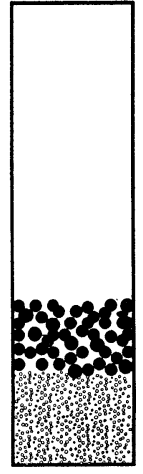

(a)

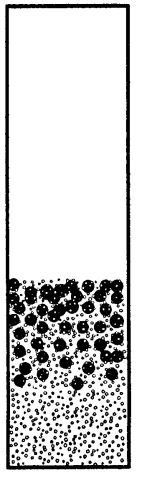

(b)

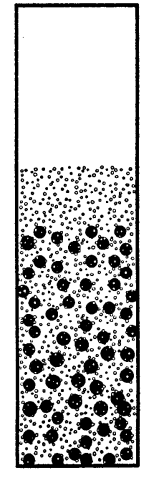

(c)

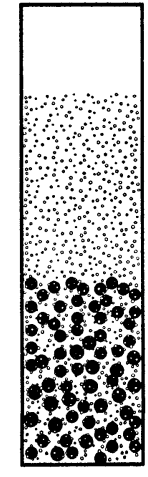

(d)
Increasing liquid velocity

Fig. 2. Stratification and mixing behavior of a binary fluidized bed with increasing superficial liquid velocity $(\bullet$, Active resin, $\bigcirc$, glass beads).

The difference between mono-component fluidized beds and binary systems becomes more pronounced with increasing liquid velocity due to the fact that more glass beads are mixed with active resins. After passing a maximum value, the mass transfer coefficient decreases with further increasing liquid velocity. The reason is the segregation of the layers leading to a decrease of the concentration of glass beads in the binary particle layer (Fig. 2 (d)).

The liquid velocity for optimal mixing state varies with the bed composition as shown in Fig. 4. To compare fluidized beds with different compositions of inert and active particles, the state of optimal mixing corresponding to mixing velocity $u_{\mathrm{m}}$ is chosen. Binary mixtures with different volumetric fractions of glass beads from 20 to $85 \%$ are studied. Fig. 6 illustrates the experimental results. The mass transfer coefficients are plotted against the optimal Reynolds number $\mathrm{Re}_{\mathrm{m}}$ corresponding to the optimal mixing state with the mixing liquid velocity $u_{\mathrm{m}}$. As a characteristic length, the diameter of the active resins is used.

As a comparison, the results for mass transfer coefficients measured with active resins in a mono-component system are shown in the same figure as a function of the Reynolds number. As can be seen, the presence of smaller inert particles in the layer of active resins leads to a significant increase in the mass transfer coefficient. At the highest concentration of inert particles, the observed mass transfer coefficient in the binary mixing layer is up to $20 \%$ higher compared to the mono-particle system.

\section{Discussion}

The value of the mass transfer coefficient $k_{\mathrm{L}}$ with binary solid particles is substantially higher than that measured without the inert particles at the same liquid velocity. The increase in mass transfer coefficient can be explained by an intensification of turbulence near the surface of the active particles. The disturbances produced by the small particles upon the transfer interface of active resins leads to a reduction of the thickness of liquid film around the active resins. In consequence, the mass transfer resistance is decreased.

In order to present the effect of smaller/heavier inert particles on the mass transfer rate in a systematic way, the experimental results for binary and mono-

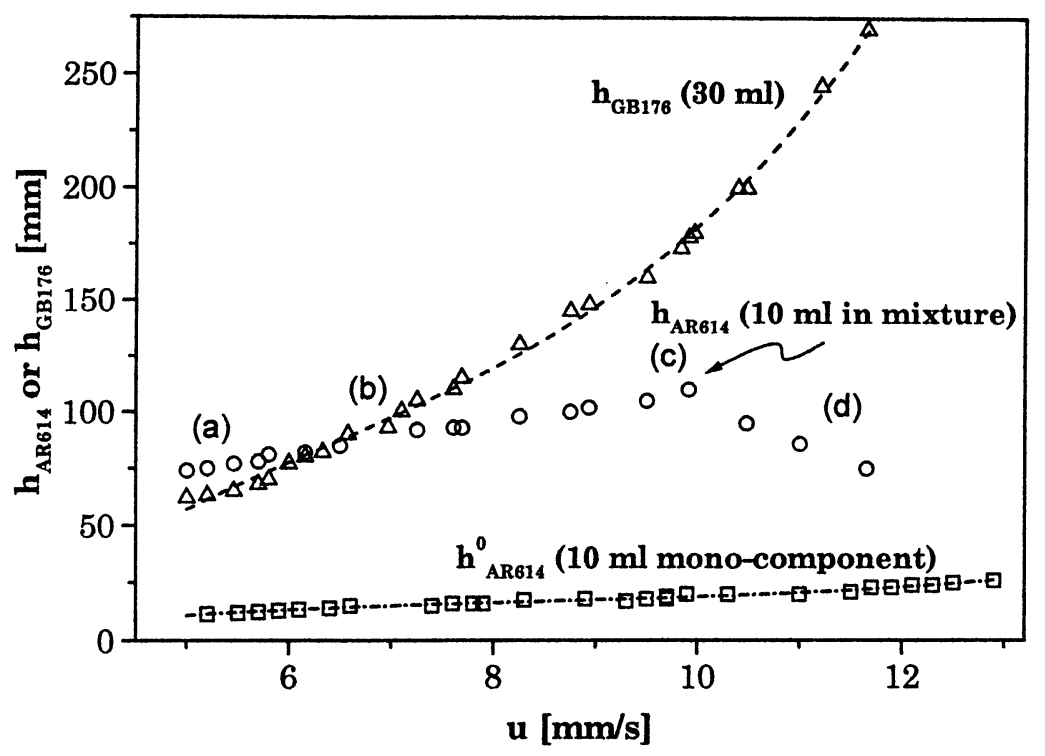

Fig. 3. Expansion characteristic of binary layer and mono-component fluidized beds. 


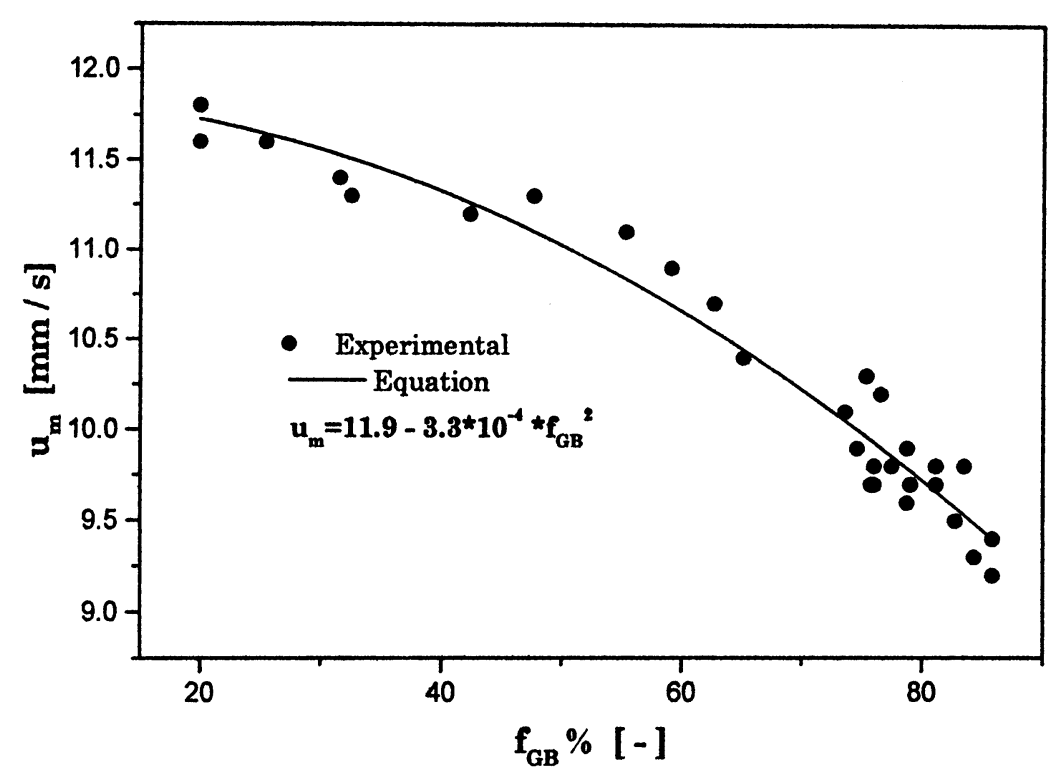

Fig. 4. Mixing liquid velocity as a function of the volume fraction of glass beads in the mixing layer.

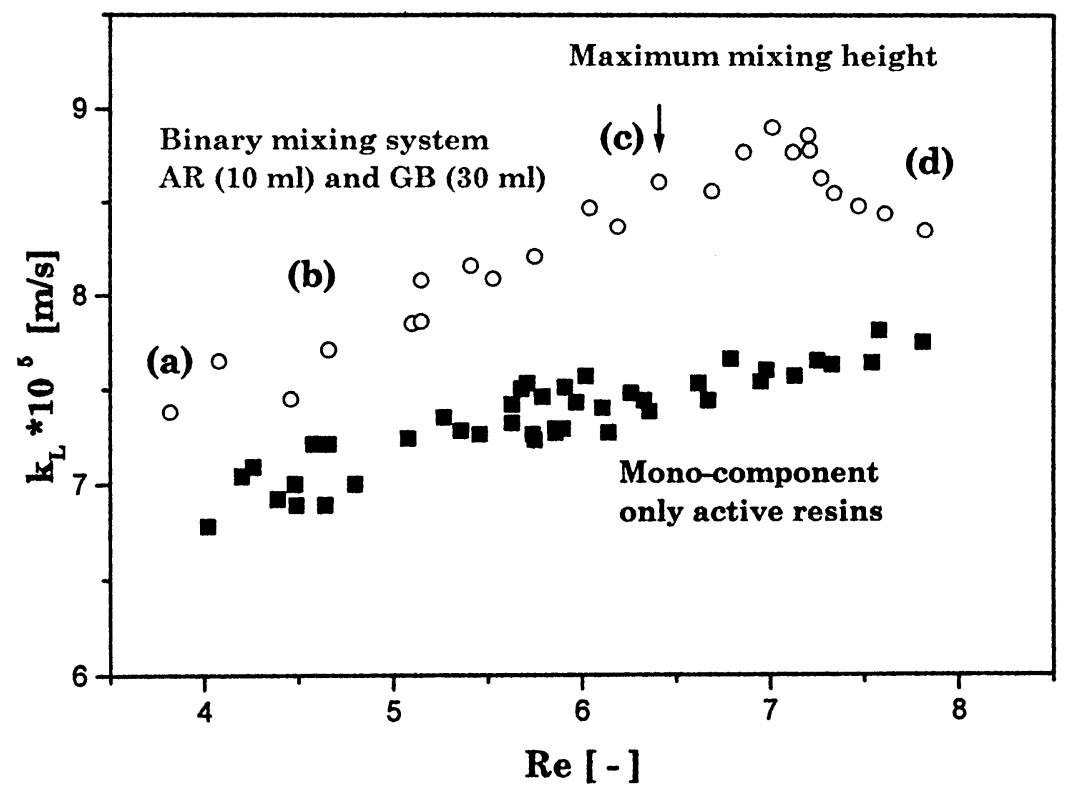

Fig. 5. Effect of inert particles on the mass transfer coefficients as a function of Reynolds number.

component systems are correlated in a dimensionless form. Theoretical predictions and experimental correlations of mass transfer rates for single particles from the literature [20-24] are as follows:

$\mathrm{Sh}=2+B_{1} \mathrm{Re}^{1 / 2} \mathrm{Sc}^{1 / 3}$

$\mathrm{Sh}=B_{2} \mathrm{Re}^{1 / 2} \mathrm{Sc}^{1 / 3}$

Eq. (9) shows that $\mathrm{Sh} \rightarrow 2$ as $\mathrm{Re} \rightarrow 0$, which is a theoretical value in the absence of convection. For practical purposes, particularly at moderate flow rates, the limiting value 2 in Eq. (9) is negligible compared to the second term. Therefore, Eqs. (9) and (10) are virtually identical. The value of the coefficient $B_{2}$ is found to be between 0.55 and 0.95 [25-31].

Mass transfer between fluidized solid particles and liquid has been studied extensively over a wide range of Reynolds numbers. It appears that most of the reported experimental data can be adequately described by the following correlation [18, 32-34]:

$$
\mathrm{Sh}=(0.81 \pm 0.05) \varepsilon^{-1} \mathrm{Re}^{1 / 2} \mathrm{Sc}^{1 / 3} \quad(1<\operatorname{Re}<1000)
$$

The voidage $\varepsilon$ accounts for the effect of the concentration of neighboring particles.

In Fig. 7, the correlation (Eq. (11)) is compared to the observed mass transfer coefficients with the monocomponent system. The experimental results agree well 
with the correlations proposed in the literature.

$\mathrm{Sh}=0.82 \varepsilon^{-1} \operatorname{Re}^{1 / 2} \mathrm{Sc}^{1 / 3} \quad(4<\operatorname{Re}<10)$

The mass transfer for a binary system is presented in the same form to allow the comparison with monocomponent systems:

$\mathrm{Sh}=B_{3} \varepsilon^{-1} \mathrm{Re}_{\mathrm{m}}^{\alpha} \mathrm{Sc}^{1 / 3}$

In this correlation, $\mathrm{Re}_{\mathrm{m}}$ is the mixing Reynolds number which is calculated at optimal mixing liquid velocity for different fractions of glass beads $f_{\mathrm{GB}}$ (Fig. 4). The method of ordinary least-squares regression has been used to fit the experimental data. The final correlation proposed for the binary particle system is given by the following relationship:

$\mathrm{Sh}=7.55 \varepsilon^{-1} \mathrm{Re}_{\mathrm{m}}^{-0.6} \mathrm{Sc}^{1 / 3} \quad\left(5<\mathrm{Re}_{\mathrm{m}}<8 ; 0.7<\varepsilon<0.9\right)$

The most striking difference in the behavior of the binary system compared to a mono-component fluidized bed is the decrease of the mass transfer coefficient with the optimal mixing Reynolds number $\mathrm{Re}_{\mathrm{m}}$. This result can be explained by the fact that smaller amounts of inert particles are retained in the mixing

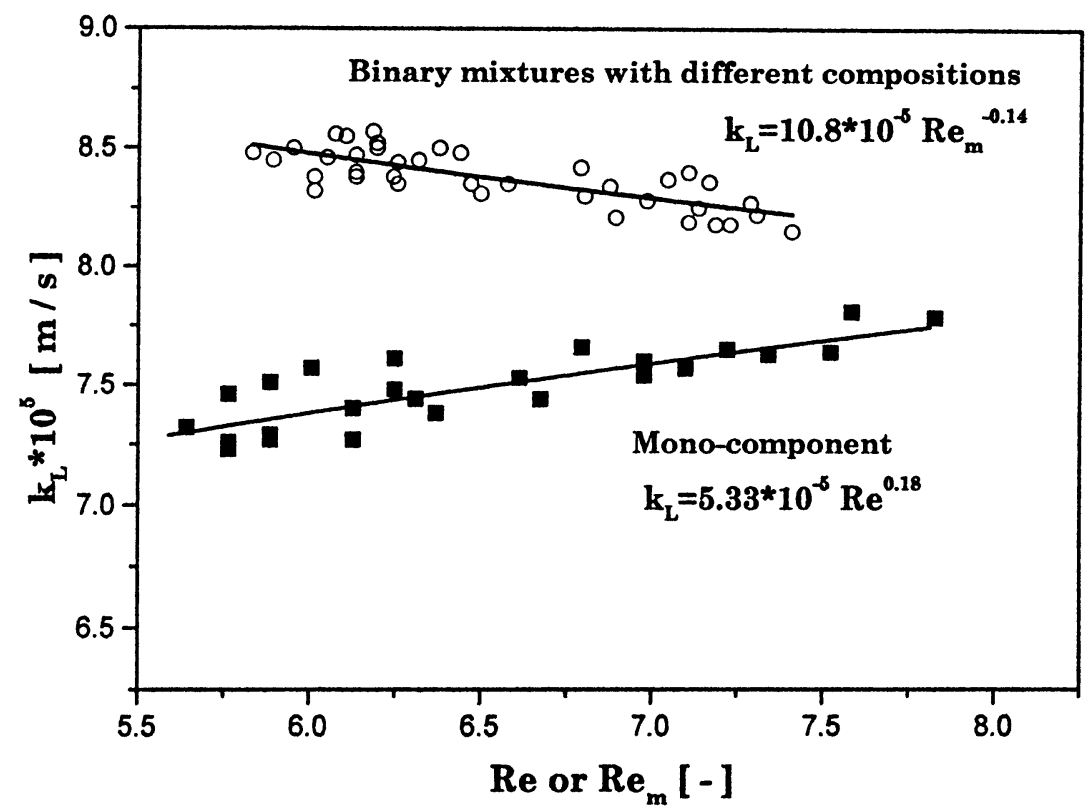

Fig. 6. Influence of Reynolds number on the mass transfer coefficients in binary- and mono-component fluidized beds

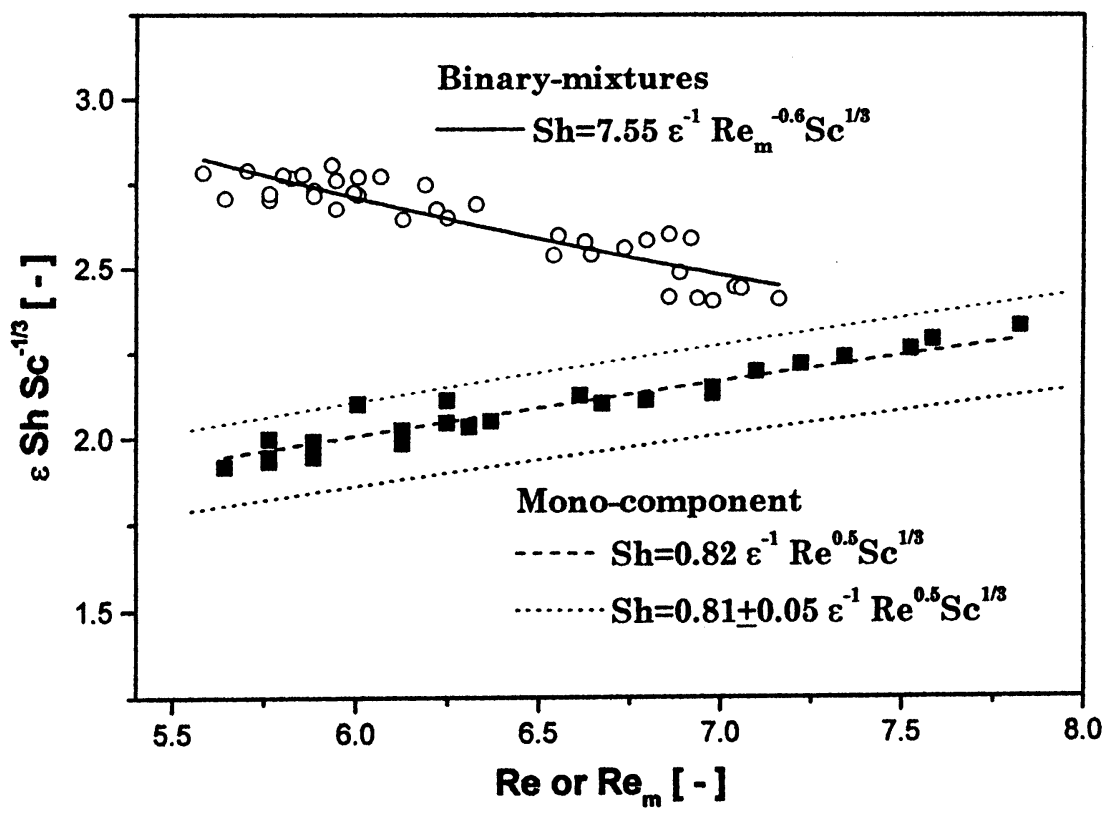

Fig. 7. Experimental results compared to predicted mass transfer coefficient in binary- and mono-component fluidized beds 
layer when the optimal mixing liquid velocity $u_{\mathrm{m}}$ increases. Therefore, higher values of $\mathrm{Re}_{\mathrm{m}}$ correspond to lower concentrations of the smaller inert particles in the mixing layer leading to reduced mass transfer coefficients. Another reason for the observed phenomena is the fact that the voidage of the mixing layer under optimal conditions decreases also with increasing liquid velocity. Finally, the mass transfer coefficient for binary systems have to meet the curve of the monoparticle system for $f_{\mathrm{GB}} \rightarrow 0$.

\section{Conclusions}

In the present paper, the mixing characteristics for binary spherical solids of different density and size is studied. The influence of the mixing state and volumetric fraction of inert particles on mass transfer of active particles are systematically investigated.

Significant enhancement of mass transfer coefficients between particles and liquid can be achieved in fluidized beds by mixing smaller/heavier inert particles with larger active particles. This experimental fact indicates that the smaller/heavier inert particles can be used to intensify the turbulence near the surface of the active particles, thus reducing the thickness of the diffusion layer and therefore the mass transfer resistance.

The obtainable enhancement of $k_{\mathrm{L}}$ depends on the fraction of inert particles in the binary mixture layer.

The solid-liquid mass transfer coefficients of binary-mixture are well correlated by Eq. (14) in terms of the dimensionless form.

\section{Acknowledgements}

Financial support by the Commission for Technology and Innovation, Switzerland is gratefully acknowledged

\section{Appendix A. Nomenclature}

$A$ total surface area of particles in fluidized bed $\left(\mathrm{m}^{2}\right)$

Ar Archimedes number, $\operatorname{Ar}=\bar{d}_{\mathrm{p}}^{3}\left(\rho_{\text {ap }}-\rho\right) \rho g / \mu^{2}(-)$

$B_{i}$ constant $(-)$

$C_{\text {in }}$ inlet concentration of sodium hydroxide (mmol $\left.1^{-1}\right)$

$C_{\text {out }}$ outlet concentration of sodium hydroxide $\left(\mathrm{mmol} \mathrm{1} \mathrm{l}^{-1}\right)$

$f \quad$ volumetric fractions of solid particles $(-)$

$\bar{d}_{\mathrm{p}} \quad$ mean particle diameter $(\mathrm{m})$

$D$ diffusion coefficient $\left(\mathrm{m}^{2} \mathrm{~s}^{-1}\right)$

$g$ gravity acceleration $\left(\mathrm{m} \mathrm{s}^{-2}\right)$

$h$ height of top surface of particle layer (m)

$k_{\mathrm{L}} \quad$ liquid side mass transfer coefficient $\left(\mathrm{m} \mathrm{s}^{-1}\right)$
$Q \quad$ liquid flow rate $\left(\mathrm{m}^{3} \mathrm{~s}^{-1}\right)$

$\operatorname{Re} \quad$ Reynolds number $\left(\operatorname{Re}=\rho u \bar{d}_{\mathrm{p}} / \mu(-)\right.$

$\operatorname{Re}_{\mathrm{m}}$ mixing Reynolds number $\left(\mathrm{Re}_{\mathrm{m}}=\rho u_{\mathrm{m}} \bar{d}_{\mathrm{p}} / \mu(-)\right.$

$\mathrm{Re}_{\mathrm{t}}$ terminal Reynolds number $\left(\mathrm{Re}_{\mathrm{t}}=\rho u_{\mathrm{t}} \vec{d}_{\mathrm{p}} / \mu(-)\right.$

Sc Schmidt number $(\mathrm{Sc}=\mu / \rho D)(-)$

$\mathrm{Sh} \quad$ Sherwood number $\left(\mathrm{Sh}=k_{\mathrm{L}} \bar{d}_{\mathrm{p}} / D(-)\right.$

$u \quad$ superficial liquid velocity $\left(\mathrm{m} \mathrm{s}^{-1}\right)$

$u_{\mathrm{m}} \quad$ optimal mixing liquid velocity $\left(\mathrm{m} \mathrm{s}^{-1}\right)$

$u_{\mathrm{t}} \quad$ terminal setting velocity of a single particle $\left(\mathrm{m} \mathrm{s}^{-1}\right)$

$V \quad$ volume $\left(\mathrm{m}^{3}\right)$

Greek symbols

$\varepsilon \quad$ bed voidage $(-)$

$\mu \quad$ viscosity $\left(\mathrm{kg} \mathrm{m}^{-1} \mathrm{~s}^{-1}\right)$

$\rho \quad$ liquid density $\left(\mathrm{kg} \mathrm{m}^{-3}\right)$

$\rho_{\text {ap }}$ apparent density of solid particle $\left(\mathrm{kg} \mathrm{m}^{-3}\right)$

\section{References}

[1] B.B. Pruden, N. Epstein, Stratification by size in particulate fluidization and in hindered settling, Chem. Eng. Sci. 14 (1964) 696-700.

[2] N. Epstein, B.P. LeClair, B.B. Pruden, Liquid fluidization of binary particle mixtures, Part I: Overall bed expansion, Chem. Eng. Sci. 36 (1981) 1803-1809.

[3] G. Van Duijn, K. Rietema, Segregation of liquid-fluidized solids, Chem. Eng. Sci. 37 (1982) 727-733.

[4] N. Epstein, B.P. LeClair, Liquid fluidization of binary particle mixtures, Part II: Bed inversion, Chem. Eng. Sci. 40 (1985) 1517-1526.

[5] H. Moritomi, T. Iwase, T. Chiba, A comprehensive interpretation of solid layer inversion in liquid fluidized beds, Chem. Eng. Sci. 37 (1982) 1751-1757.

[6] H. Moritomi, T. Yamagishi, T. Chiba, Prediction of complete mixing of liquid-fluidized binary solid particles, Chem. Eng. Sci. 41 (1986) 297-305.

[7] V.S. Patwardhan, C. Tien, Sedimentation and liquid fluidization of solid particles of different sizes and densities, Chem. Eng. Sci. 40 (1985) 1051-1060.

[8] R. Di Felice, L.G. Gibilaro, S.P. Walgram, P.U. Foscolo, Mixing and segregation in binary-solid liquid fluidized beds, Chem. Eng. Sci. 42 (1987) 639-652.

[9] R. Di Felice, L.G. Gibilaro, P.U. Foscolo, On the inversion of binary-solid liquid fluidized beds, Chem. Eng. Sci. 43 (1988) 979-981.

[10] R. Di Felice, Mixing in segregated, binary-solid liquid-fluidized beds, Chem. Eng. Sci. 48 (1993) 881-888.

[11] L.G. Gibilaro, R. Di Felice, S.P. Walgram, P.U. Foscolo, A predictive model for the equilibrium composition and inversion of binary-solid liquid fluidized beds, Chem. Eng. Sci. 41 (1986) 379-387.

[12] R. Jean, L. Fan, On the criteria of solids layer inversion in a liquid-solid fluidized bed containing a binary mixture of particles, Chem. Eng. Sci. 41 (1986) 2811-2821.

[13] A.C. Hoffmann, L.P.B.M. Janssen, J. Prins, Particle segregation in fluidized binary mixtures, Chem. Eng. Sci. 48 (1993) 15831592.

[14] M. Asif, Generalized Richardson-Zaki correlation for liquid fluidization of binary solids, Chem. Eng. Technol. 21 (1998) 77-82. 
[15] V.L. Schiller, A. Naumann, Über die grundlegenden Berechnungen bei der Schwerkraftaufbereitung, Zeitschr. Ver. Deut. Ing. 77 (1933) 318-320.

[16] A.G. Livingston, J.B. Noble, Mass transfer in liquid solid fluidized beds of ion exchange resins at low Reynolds numbers, Chem. Eng. Sci. 48 (1993) 1174-1178.

[17] K.I. Kikuchi, H. Konno, S. Kakutani, T. Sugarawa, H. Ohashi, Axial dispersion of liquid in liquid fluidized beds in the low Reynolds number region, J. Chem. Eng. Jpn. 17 (1984) 362-367.

[18] K. Rahman, M. Streat, Mass transfer in liquid fluidized beds of ion exchange particles, Chem. Eng. Sci. 36 (1981) 293-300.

[19] N. Funamizu, T. Takakuwa, An improved Richardson-Zaki formula for computing mixed layer composition in binary solid-liquid fluidized beds, Chem. Eng. Sci. 50 (1995) $3025-$ 3032 .

[20] W.E. Ranz, W.R. Marshall, Evaporation from drops, Part I, Chem. Eng. Program. 48 (1952) 141-146.

[21] W.E. Ranz, W.R. Marshall, Evaporation from drops, Part II, Chem. Eng. Program. 48 (1952) 173-180.

[22] M. Linton, K.L. Sutherland, Transfer from a sphere into fluid in laminar flow, Chem. Eng. Sci. 12 (1960) 214-229.

[23] P.N. Rowe, K.T. Claxton, J.B. Lewis, Heat and mass transfer from a single sphere in an extensive flowing fluid, Trans. Instrum. Chem. Eng. 43 (1965) 14-31.

[24] S. Damronglerd, J.P. Couderc, H. Angélino, Transfert de matière en fluidisation liquide, Proceedings of the International Symposium on Fluidization and its Applications. Editions Cepadues, Toulouse, 1974, pp. 330-340.

[25] F.H. Garner, R.B. Keey, Mass transfer from single solid spheres, Part I: Transfer at low Reynolds numbers, Chem. Eng. Sci. 9 (1958) 119-129.

[26] F.H. Garner, R.D. Suckling, Mass transfer from a soluble solid sphere, J. AIChE 4 (1958) 114-124.

[27] R.W. Grafton, Prediction of mass transfer from spheres and cylinders in forced convection, Chem. Eng. Sci. 18 (1963) 457466.

[28] A.C. Lochiel, P.H. Calderbank, Mass transfer in the continuous phase around axisymmetric bodies of revolution, Chem. Eng. Sci. 19 (1964) 471-484.

[29] H. Gibert, J.P. Couderc, H. Angelino, Etude des transferts de matière entre une sphère et un liquide en convection forcée, Chem. Eng. Sci. 27 (1972) 45-59.

[30] G. Valentin, P. Le Goff, Fluidisation par liquide: Etude du transfert de matière entre le liquide et un objet mobile dans le lit, J. Chem. Eng. 15 (1978) 185-195.

[31] K. Rahman, M. Streat, Mass transfer to single spheres settling at their terminal velocities, Chem. Eng. Sci. 36 (1981) 301305.

[32] T. Koloini, M. Sopcic, M. Zumer, Mass transfer in liquidfluidized beds at low Reynolds numbers, Chem. Eng. Sci. 32 (1977) 637-641.

[33] C.B. Snowdon, J.C.R. Turner, Mass transfer in liquid-fluidized beds of ion exchange resin beads, Proceedings of the International Symposium on Fluidization, Netherlands University Press, Amsterdam, 1967, pp. 599-609.

[34] L.J. Petrovic, G. Thodos. Effectiveness factors for mass transfer in fluidized systems, Proceedings of the International Symposium on Fluidization, Netherlands University Press, Amsterdam, 1967, pp. 586-598. 